Faculdade de Ciências Econômicas UFRGS
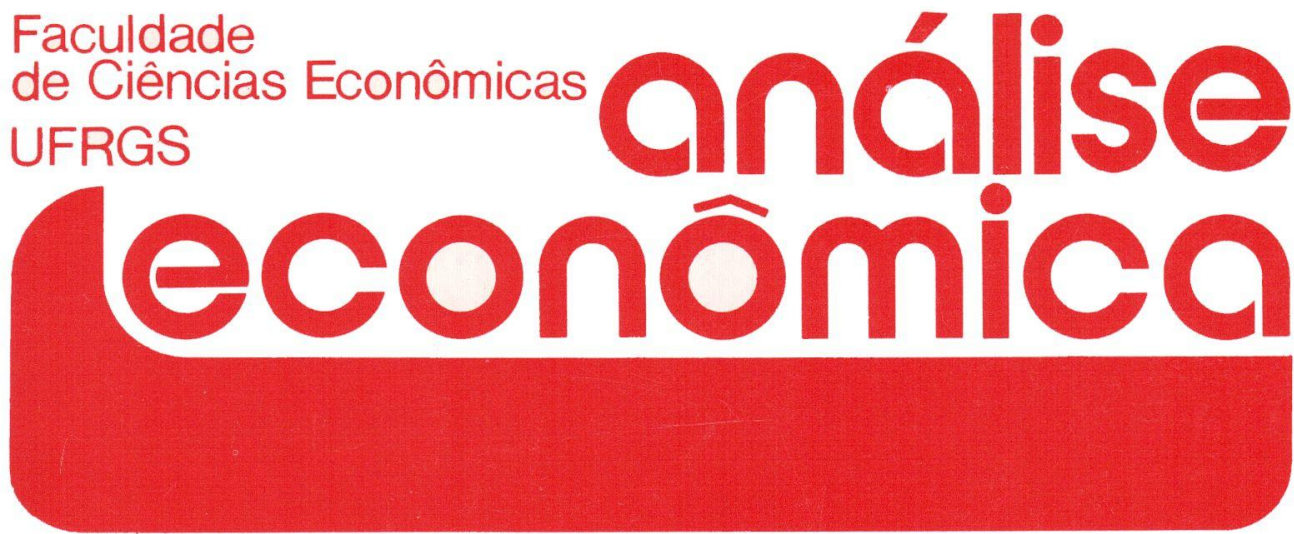

- STATE AND THE LIBERALIZATION OF THE BRAZILIAN ECONOMY

Carlos Alberto Longo

- MOEDA E CRÉDITO NA ECONOMIA BRASILEIRA: UM MODELO COM VETORES DE CORREÇÃO DE ERROS

Rolando M. Guzmán

- baSES PARA UM NOVO MOdELO DE POLítica FISCAL, PARA O BRASIL

Flávio Riani

- POR QUE OS SINOS DOBRAM? CONFLITO TRABALHISTA E SALÁRIOS DO MAGISTÉRIO PÚBLICO DO RIO GRANDE DO SUL, 1974-1991

Carlos Henrique Horn

Roberto Balau Calazans

- A POLÍtica MONETÁRIa E AS TAXAS de JUROS NO PLANO COLLOR

Lauro Lobo Burle

- DIFUSÃo E TRANSFERÊNCIA DA TECNOLOGIA DE PRODUÇÃO DE CIMENTO NO BRASIL

Maria Cristina Pereira de Melo

- SISTEMA FINANCEIRO BRASILEIRO: UMA PROPOSTA dE disCuSSÃo

Luiz Felipe Serpa

- TEORIA ECONÓMICA DO CASAMENTO E DO Divórcio

Giácomo Balbinotto Neto

- RESENHA

VARGAS: O CAPITALISMO EM CONSTRUÇÃO, DE PEDRO C. D. FONSECA

João Rogério Sanson

- LIVROS RECEBIDOS

Claudine Saldanha César
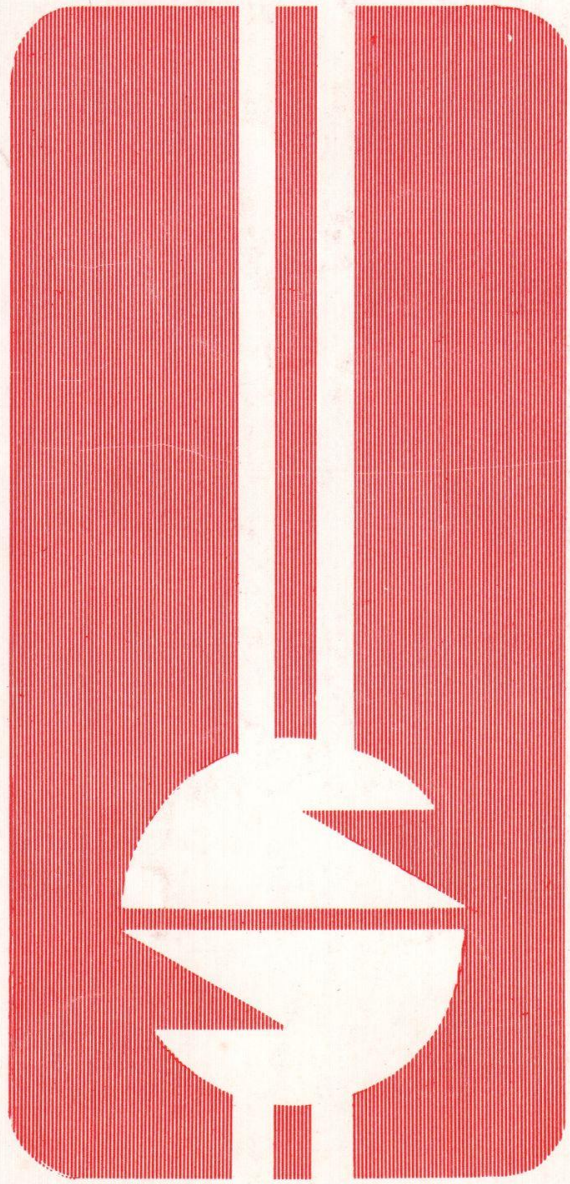
UNIVERSIDADE FEDERAL DO RIO GRANDE DO SUL

Reitor: Prof. Hélgio Henrique Casses Trindade

FACULDADE DE CIÉNCIAS ECONÔMICAS

Diretora: Prof ${ }^{a}$ Yeda Rorato Crusius

CENTRO DE ESTUDOS E PESQUISAS ECONÔMICAS

Diretor: Reinaldo Ignacio Adams

DEPARTAMENTO DE CIENNCIAS ECONÔMICAS

Chefe: Prof. Fernando Ferrari Filho

CURSO DE PÓS-GRADUAÇÃO EM ECONOMIA

Coordenador: Prof. João Rogério Sanson

CURSO DE PÓS-GRADUAÇÃO EM ECONOMIA RURAL

Coordenador: Prof. Juvir Luiz Mattuella

CONSELHO EDITORIAL: Achyles Barcelos da Costa, Aray Miguel Feldens, Atos Freitas Grawunder, Carlos Augusto Crusius, ErnaniHickmann, Fernando Ferrari Filho, João Rogério Sanson, Juvir Luiz Mattuella, Maria Imilda da Costa e Silva, Nali de Jesus de Souza, Nuno Renan Lopes de Figueiredo Pinto, Otília Beatriz Kroeĩ Carrion, Otto Guilherme Konzen, Paulo Alexaridre Spohr, Pedro Cezar Dutra Fonseca, Reinaldo Ignacio Adams, RobertsCamps Moraes, Valter José Stülp, Yeda Rorato Crusius, David Garlow (Wharton Econometrics Forecasts Association, E.U.A.), Edgar Augusto Lanzer (UFSC), Eleutério F. S. Prado (USP), Fernando Holanda Barbosa (FGV/RJ), Gustavo Franco (PUC/RJ), Joaquim Pinto de Andrade (UiNB), Juan H. Moldau (USP), Werner Baer (Univ. de Illinois, E.U.A.)

COMISSÃO EDITORIAL: Atos Freitas Grawunder, Reinaldo Ignacio Adams, Pedro Cezar Dutra Fonseca, Roberto Camps Moraes.

EDITOR: Nali Jesus de Souza

SECRETARIA: Maria Ivone de Mello (normalização), Vanete Ricacheski (revisão de textos)

FUNDADOR: Prof. Antônio Carlos Santos Rosa

Os materiais publicados na Revista Análise Econômica são de exclusiva responsabilidade dos autores. É permitida a reprodução total ou parcial dos trabalhos, desde que seja citada a fonte.

Aceita-se permuta com revistas congêneres. Aceitam-se, também, livros para divulgação, elaboração de resenhas ou recensões.

Toda correspondência, material para publicação (vide normas na $3^{a}$ capa), assinaturas e permutas devem ser dirigidos ao seguinte destinatário:

PROF. NALI DE JESUS DE SOUZA

Revista Análise Econômica

Av. João Pessoa, 52

90040-000 - PORTO ALEGRE (RS), BRASIL

Telefones: (051) 228.1633 - 224.6022 - Ramais 3348 ou 3440

FAX: (051) 225.1067 


\section{A POLÍTICA MONETÁRIA E AS TAXAS DE JUROS NO PLANO COLLOR}

\section{Lauro Lobo Burle *}

\section{SINOPSE}

Este artigơanalisa a política monetária, as taxas de juros e as aplicações em depósitos a prazo durante o Plano Collor. Zurabalho pretende evidenciar que o aperto de liquidez e o descontrole dos preços acentuaram a escassez de crédito de longo prazo, assim como transformaram os depositos a prazo no principal ativo financeiro em poder do público.

\section{INTRODUÇÃO}

No dia 15 de março de 1990, o Banco Central confiscou por um ano e meio cerca de $70 \%$ dos ativos financeiros do setor privado, acentuando o processo de redução da poupança financeira registrado pela economia brasileira desde meados da década de 80(Martone, 1991; Yoshino \& Lundberg, 1991). Por outro lado, após vinte meses do Plano Collor, verifica-se que a reforma financeira não alcançou um dos seus principais objetivos, ou seja, o alongamento do prazo dos empréstimos e das aplicações do sistema financeiro. Constata-se que as captações se conceritram em Certificados de Depósito Bancário (CDBs) prefivados a 30 dias, o que se explicou em grande parte pela liquidez apertada e descontrole dos preços desse plano de estabilização.

Este artigo está organizado da seguinte forma: na seção 2, analisa-se a política monetária, desde a adoção do Plano Collor aié a segunda metade de 1991; na seção 3, discutem-se os prinçipais aspectos das aplicações em depósitos a prazo e das taxas de juros desse programa de ajustamento e; na seção 4 , apresentam-se as considerações finais.

* Da Faculdade de Economia do Centro de Ensino Unificado de Brasília (CEUB)

\begin{tabular}{|l|l|l|l|l|}
\hline ANÁLISE ECONÔMICA & ANO 10 & N:18 & SETEMBRO/92 & P.83-94 \\
\hline
\end{tabular}




\section{POLÍTICA MONETÁRIA ${ }^{1}$}

Em março de 1990, o Banco Central confiscou quase três quartos da poupança financeira por 18 meses, impôs o Imposto sobre Operações Financeiras (IOF) (de uma única vez) sobre o resgate das aplicações, reduziu o prazo de recolhimento do exigível compulsório de quinzenal para semanal (Circular $\mathbf{n}^{\mathbf{0}}$ 1601) e dividiu os bancos em dois grupos, visando o maior controle das reservas bancárias. Posteriormente, em face do aperto da liquidez resultante das medidas acima, a autoridade monetária cobriu as deficiências em cruzados das instituições financeiras nas reservas bancárias e abriu linha especial de crédito para o pagamento de salários (Resolução n 1697).

No entanto o rápido aumento da liquidez propiciado pela devolução legal e extra-legal da moeda confiscada levou o Conselho Monetário Nacional (CMN), já em máio, a estabelecer metas rígidas de expansão monetária, prevendo-se para o Ml (papel moeda em poder do público mais depósitos à vista) expansão nominal de $2 \%$ entre julho e setembro; $7 \%$ entre outubro e dezembro e; $0 \%$ entre janeiro e março de 1991. Para o M4 (M1 mais títulos públicos em poder do público, depósitos de poupança e títulos privados) ficou estabelecido $6,1 \%$ entre julho e setembro; 4, $8 \%$ entre outubro e dezembro e; $0 \%$ entre janeiro e março de 1991. Além do mais, o Banco Central reduziu o crédito ao consumo (Resolução no ${ }^{1708 \text {, }}$ alterada pela de $\mathrm{n}$ - 1715); voltou a realizar leilões formais de venda de Letras do Tesouro Nacional (LTNs), objetivando regular a liquidez (havia deixado de fazêlo em março); e extiguiu a garantia de recompra automática das posições diárias das instituições que operam no mercado aberto. ${ }^{2}$

Em agosto de 1990, a autoridade monetária ampliou a base de recolhimento do compulsório sobre depósitos à vista, incluindo recursos de trânsito, cheques administrativos e as cobranças e as arrecadações de tributos (Circular $n^{\circ} 1805$ ) e, elevou os encargos das das linhas de redesconto. Em janeiro de 1991, foram lançados no mercado os Bônus do Banco Central (BBCs) (título prefixado de curtć prazo) e, em março, foram extintas as aplicações em "overnight" para pessoas físicas e jurídicas não-finance iras e elevados, mais uma vez, os custos das linhas de redesconto. Ademais, em 1991 o Banco Central se destaco: neutralizando a posição sobrevendida em títulos públicos em relação ao nível de reservas das instituições ("oversold"), com a venda de dinheiro em leilões informais ("goarounds"), o que, na prática, funcionou como o extinto mecanismo da recompra automática.

A experiência histórica acumulada desde 1986 indica que, após os programas de estabilização, a oferta de moeda sempre aumenta. ${ }^{3}$ De fato, entre fevereiro

1 Esta seção foi extraída, em parte. de Burle (1991).

Veja, por exemplo, Pereira \& Nakano (1991), Nakano (1990) e Pastore (1990).

Sobre o Plano Cruzado, veja, por exemplo, Moraes (1990) 
e maio de 1990 os saldos nominais da base monetária (papel moeda em circulação mais reservas bancárias) e do Ml (dados de fins de mês; veja Tabela l) aumentaram $558,2 \%$ e $442,2 \%$, respectivamente, enquanto que a inflação acumulada pelo IGP/ FGV (Índice Geral de Preços da Fundação Getúlio Vargas) foi de $120,1 \%$. No mesmo período, os empréstimos do sistema financeiro ao setor privado cresceram apenas $78,6 \%$, refletindo o racionamento e o aperto da liquidez na ponta de crédito.

TABELA 1

SALDOS MENSAIS DA MOEDA E DO CRÉDITO (Cr\$ bilhões) 1990-1991

\begin{tabular}{c|c|c|c}
\hline MESES & $\begin{array}{c}\text { BASE } \\
\text { MONETÁRIA }\end{array}$ & $\begin{array}{c}\text { MEIOS DE } \\
\text { PAGAMENTO(MI) }\end{array}$ & $\begin{array}{c}\text { EMPRÉSTIMOS } \\
\text { AO SETOR PRIVADO }\end{array}$ \\
\hline Fev. & 140,0 & 224,3 & $2.559,4$ \\
Mar. & 342,4 & 659,6 & $4.420,9$ \\
Abr. & 582,1 & 894,1 & $4.956,1$ \\
Mai. & 921,5 & $1.216,2$ & $4.571,9$ \\
Jun. & 836,8 & $1.209,9$ & $5.092,9$ \\
Jul. & 761,6 & $1.209,3$ & $5.806,2$ \\
Ago. & 781,6 & $1.321,4$ & $6.563,7$ \\
Set. & 921,4 & $1.515,3$ & $7.548,4$ \\
Out. & 919,8 & $1.518,6$ & $8.721,1$ \\
Nov. & $1.026,3$ & $1.810,9$ & $10.186,1$ \\
Dez. & $1.621,3$ & $2.510,2$ & $12.215,0$ \\
Jan. & $1.309,1$ & $2.138,7$ & $14.515,9$ \\
Fev. & $1.812,1$ & $3.231,5$ & $15.500,3$ \\
Mar. & $2.023,8$ & $3.441,0$ & $16.227,4$ \\
Abr. & $2.027,0$ & $3.500,3$ & $18.771,8$ \\
Mai. & $2.249,5$ & $3.777,1$ & $20.371,7$ \\
Jun. & $2.474,9$ & $4.411,3$ & n.a. \\
Jul. & $2.571,3$ & $4.341,2$ & n.a. \\
Ago. & $2.812,2$ & $4.981,2$ & n.a. \\
Set. & $3.209,9$ & $6.139,4$ & n.a. \\
\hline
\end{tabular}

- Saldos de fim de mês.

FONTE: Banco Central (1991ă). 
Entre maio e outubro, verifica-se pela Tabela 1 que os saldos nominais da base monetária e do $\mathrm{Ml}$ se mostraram relativamente estáveis, embora tenha ocorrido diversos fatores de pressão da liquidez, tais como redistribuição de ativos financeiros em face do IOF (Resolução n 1706), ampliação da base de recolhimento do compulsório sobre depósitos à vista e liquidação de bancos estaduais.

Em novembro, já era evidente que a programação monetária traçada em maio havia sido superada. De fevereiro a dezembro de 1990, o saldo de base monetária variou $1.058,1 \%$, enquanto que a inflação medida pelo IGP/FGV foi de apenas $434,1 \%$. No mesmo período, o estoque do crédito total do sistema financeiro ao setor privado aumentou $377,3 \%$ indicando que, se por um lado, houve expansão real da oferta monetária, por outro lado, houve aperto de liquidez na política de crédito.

O Plano Collor obteve relativo êxito na contenção da alta dos preços noś três primeiros meses, ou seja, até junho de 1990. Posteriormente, entretanto, a inflação voltou ao patamar dos dois dígitos e, em janeiro de 1991, as autoridades governamentais adotaram o Plano Collor 2, contendo congelamento de preços e salários, reforma financeira e "tarifaço". "Verifica-se, pela Tabela 2, que a inflação, mesmo após esse choque, passou de $19,9 \%$ em janeiro para $21,1 \%$ em fevereiro, explicado principalmente pelo impacto de custos dos reajustes das tarifas públicas.

Entre março e maio de 1990, as taxas de juros do "overnight" fixadas pelo Banco Central foram negativas em termos reais (v. Tabela 2). De junho a agosto desse ano, as taxas de juros mais ou menos acompanharam a inflaçãoe de setembro a dezembro as taxas de juros e os "spreads" (diferença entre as taxas de captação e as taxas de aplicação) se elevaram para patamares positivos em termos reais, se refletindo diretamente na ponta dos empréstimos (v. Tabelas $2 \mathrm{e} 3$ ). Contribuíram, para este comportamento do último quadrimestre, a política econômica instável e a incidência de impostos no mercado financeiro.

Em fevereiro de 1991, o governo fixou a Taxa Referencial de Juros (TR) em $7 \%$ enquanto que a inflação foi de $21,1 \%$, o que provocou novo confisco das apiicações financeiras, principalmente em títulos pós-fixadoc De março a julho

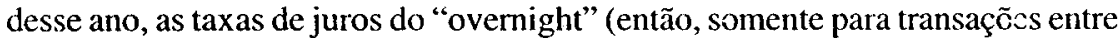
as instituicões financeiras) se situaram um pouco acima das taxas mensais de inflação (v. Tabela 2). Finalmente, a partir de agosto, o Banco Central elevou as taxas de juros, tendo em vista o início da devolução dos cruzados novos.

4 Sobre os motivos iniciais do descontrole dos preços do Plano Collor, veja Pereira \& Nakano (1991) 
TABELA 2

TAXAS DE JUROS E DE INYLAÇÃO (\%)

1990-1991

\begin{tabular}{c|c|c}
\hline MESES & OVERNIGHT & IGP/FGV \\
\hline Mar. & 36,8 & 81,3 \\
Abr. & 4,2 & 11,3 \\
Mai. & 5,7 & 9,1 \\
Jun. & 8,7 & 9,0 \\
Jul. & 13,8 & 13,0 \\
Ago. & 11,5 & 12,9 \\
Set. & 15,2 & 11,7 \\
Out. & 16,5 & 14,2 \\
Nov. & 19,8 & 17,4 \\
Dez. & 22,9 & 16,5 \\
Jan. & 21,0 & 19,9 \\
Fev. & 6,9 & 21,1 \\
Mar. & 9,0 & 7,3 \\
Abr. & 9,7 & 8,7 \\
Mai. & 9,6 & 6,5 \\
Jun. & 10,3 & 9,9 \\
Jul. & 12,4 & 12,8 \\
Ago. & 15,8 & 15,5 \\
Set. & 19,8 & 16,2 \\
\hline ACUMULADO & $1,097,2$ & $1.502,8$ \\
\hline
\end{tabular}

FONTE: Banco Central (199lb).

Obs.: A partir de março de 1991, as aplicações em "overnight" passaram a ser efetuadas somente para instituições financeiras.

TABELA 3

TAXAS DE JUROS DOS EMPRÉSTIMOS (\%)

-1990 -

\begin{tabular}{c|c|c|c|c|c}
\hline MESES & $\begin{array}{c}\text { CRÉDITO } \\
\text { HOT-MONEY } \\
\text { (I a 7 dias) }\end{array}$ & $\begin{array}{c}\text { CAPITAL DE GIRO } \\
\text { PREFIXADO } \\
\text { (A 30 DIAS) }\end{array}$ & $\begin{array}{c}\text { CRÉDITO } \\
\text { AO CONSUMO } \\
\text { (BANCOS) }\end{array}$ & $\begin{array}{c}\text { CRÉDITO } \\
\text { AO CONSUMO } \\
\text { (LOJAS) }\end{array}$ & $\begin{array}{c}\text { CRÉDITO } \\
\text { PESSOAL }\end{array}$ \\
\hline Out. & 34,0 & 25,0 & 30,0 & 35,0 & 35,0 \\
Nov. & 36,0 & 25,0 & 35,0 & 40,0 & 50,0 \\
Dez. & 31,0 & 22,0 & 35,0 & 40,0 & 50,0 \\
\hline
\end{tabular}

FONTE: Sartori (1990).

Obs: Taxas de juros dos dias 13/out., 16/nov. e 14/dez. 
TABELA 4

VARIAÇÕES MENSAIS DO FAF, TR E INFLAÇÃO EM 1991 (\%)

\begin{tabular}{crrc}
\hline MESES & FAF & TR & IGP/FGV \\
\hline Mar. & 8,7 & 8,5 & 7,3 \\
Abr. & 9,3 & 8,9 & 8,7 \\
Mai & 9,2 & 8,9 & 6,5 \\
Jun. & 9,3 & 9,4 & 9,9 \\
Jul. & 10,4 & 10,1 & 12,8 \\
Ago. & 12,5 & 11,9 & 15,5 \\
Set. & 16,7 & 16,8 & 16,2 \\
Out. & 19,7 & 19,8 & 25,9 \\
\hline ACUMULADO & 146,1 & 142,7 & 160,2 \\
\hline
\end{tabular}

FONTE: Bittencourt (1991a).

Obs.: Rendiuiento médio dos 10 maiores FAFs.

\section{DEPÓSITOS A PRAZO E TAXAS UE JUROS ${ }^{5}$}

Em março de 1991, o Banco Central operacionalizou o Fundo de Aplicações Financeiras (FAF). ${ }^{6}$ OFAF (ou Fundão) foi uma iniciativa do governo para alongar as aplicações financeiras e alocar recursos em inversões fixas. Para ilustrar isso, entre junho e outubro de 1991 o Banco Nacional de Desenvolvimento Econômico e Social (BNDES) aprovou mais de US\$600 milhões de dólares em investimentos industriais com recursos captados pelo Fundão, ou seja, com a emissão de Títulos' de Desenvolvimento Econômico (TDEs) pelas instituições financeiras.

Conforine se verifica pela Tabela 4, de iuarço a outubro de 1991 o rendimento médio dos dez maiores FAFs acumulou uma variação de $146,1 \%$, enquanto que a inflação medida pelo IGP/FGV foi de $160,2 \%$. Uma das razões para essa performance negativa foi a composição do lastro do Fundão, assentado parcialmente em aplicações indexadas pela TR. ${ }^{7}$ Como esta subestimcu a inflação no período (v. Tabela 4), a rentabilidade do FAF foi influenciada negativamente.

5 Esta seção foi extraída, em parte, de Burłe (1991 e 1992).

6 Sobre os aspectos da reforma financeira dessa seção, veja tanıbém Simonsen (1991), Toledo(1991) e Yoshino (1991a e 1991b).

7 As aplicações indexadas pela TR se constituem por $23 \%$ de depósitos no Banco Central, $10 \%$ por Títulos de Desenvolvimento Econômico, $3 \%$ por cotas do Fundo de Desenvolvimento Social, uma parcela dos $42 \%$ que cabem aos títulos estaduais e privados e outra dos $20 \%$ cabem aos títulos federais. 
Outra razão residiu na movimentação de saques e de depósitos de grandes empresas, o que fez incidir o IOF.

Criada em janeiro, a TR se baseia na média das taxas de juros dos CDBs prefixados de 30 dias praticadas pelos bancos e ponderada pelo volume negociado nos seis primeiros dias úteis do mês de vigência. ${ }^{8}$ Pelos dados da Central de Custódia e Liquidação de Títulos Privados (Cetip), do valor de $\operatorname{Cr} \$ 8,8$ trilhões de CDBs em custódia do dia 18 de dezembro (ao redor de $70 \%$ do total do mercado), ${ }^{9}$ $81,6 \%$ eram títulos prefixados de 30 dias e o restante papéis pós-fixados de prazos acima de 90 dias (principalmente de indexação pela TR ou Taxa Referencial Diária - TRD), indicando a preferência dos investidores pelas aplicações com o risco da inflação. ${ }^{10}$ O que justifica a baixa adesão da TR entre os investidores, mesmo sendo $o$ indexador oficial do mercado financeiro?

Além da aversão dos agentes às aplicações pós-fixadas incorporada com as tablitas, a base tomada das taxas dos CDBs do início do mês faz a TR subestimar a alta dos preços num contex to de aumento da inflação, tal como de maio a outubro de 1991 (v. Tabela 4). Outra razão da pouca credibilidade da TR são as elevadas oscilações das taxas dos CDBs em virtude da alteração da liquidez propiciada pelc recolhimento de impostos e contribuiçôes do INSS/FGTS, compulsório sobre depósitos à vista, pagamento de salários, resgates e emissões de títulos públicos e privados, entre outros fatores. Talvez mais adequado seria tomar as taxas de juros do "overnight" fixadas pelo Banco Central e utilizadas como custo primário do dinheiro transacionado por um dia entre as instituições financeiras (Yoshino, 1991a).

Vale notar que, em outros países, a taxa flutuante de juros é formada a partir das taxas de juros do over interbancário, o que equivale aos Certificados de Depósito Interbancário (CDIs) negociados por um dia no Brasil. No entanto as taxas de juros deste mercado tendem a oscilar mais do que as dos CDBs prefixados de trinta dias. Em síntese, a taxa flutuante de juros brasi!eira como referencial para empréstimos parece ainda distante, em razão, sobretudo, da política monetária volátil resultante do déricit público.

Por outro lado, os depósitos a prazo (CDBs) se transformaram nn principal ativo financeiro em poder do público, atingindo o saldo de $\mathrm{Cr} \$ 7,6$ trilhões (dados do Banco Central) em julho de 1991 , dentro de uma poupança total de $\mathrm{Cr} \$ 25,8$ trilhões no conceito amplo de meios de pagamento M4, que inclui papel moeda em poder do público, depósitos à vista, títulos públicos em poder do mercado,

8 Até outubro de 1991, tomava-se os três uitimos dias úteis do mês e os três primeiros dias úteis após o primeiro dia útil do mês seguinte (o de vigência). A Resoluçäo n 1.878 de 25 de outubro, alterou para a forma apresentada no texto.

9 Vale acrescentar que a Cetip não registra uma parcela de CDBs, que é custodiada pelas proprias instituições financeiras.

10 Em janeiro de 1991 (antes do Plano Collor 2) a proporção de títulos prefixados no estoque total de CDBs era de apenas $60 \%$. 
depósitos de poupança e títulos privados (v. Tabela 5). ${ }^{11}$ Ademais, em maio de 1991 (últimos dados oficiais desagregados), os bancos múltiplos tinham $66,1 \%$ das emissões de CDBs - totalizando $\mathrm{Cr} \$ 6,1$ trilhões, inclusive a carteira das instituições - os bancos comerciais 12,5\%, o Banco do Brasil 10,5\% e as demais instituições financeiras (caixas econômicas, bancos de investimento e bancos de desenvolvimento) 10,9\% (Banco Central, 1991a).

TABELA 5

OS CDBs E A POUPANÇA FINANCEIRA (Cr\$ bilhões) 1990-1991

\begin{tabular}{l|c|c|c}
\hline MESES & $\begin{array}{c}\text { CDBs } \\
(1)\end{array}$ & $\begin{array}{c}\text { M4 } \\
(2)\end{array}$ & $(3)=\frac{(1)}{(2)}(\%)$ \\
\hline Fev. & 318,7 & $3.551,7$ & 8,9 \\
Mai. & 547,4 & $4.477,2$ & 12,2 \\
Ago. & $1.294,1$ & $6.218,3$ & 20,8 \\
Nov. & $2.305,9$ & $9.204,5$ & 25,1 \\
Fev- & $3.130,2$ & $14.866,9$ & 21,1 \\
Mai. & $5.869,5$ & $20.341,8$ & 28,9 \\
Jul. & $7.594,5$ & $25.774,5$ & 29,5 \\
\hline
\end{tabular}

FONTE: Banco Central (1991a e 1991c).

Nota: M4:Papel-moeda em poder do público, depósitos à vista, títulos federais em poder do público, exclusive carteiras das instituições, títulos estaduais e municipais em poder do público, depósitos de poupança, depósitos a prazo, exclusive carteira das instituiçôes, letras de câmbio e letras hipotecárias.

Conforme notado anteriormente, segundo a Cetip, ao final de 1991 mais de $80 \%$ do estoque de CDBs se constituíam por papéis prefixados de 30 dias. Além da descredibilidade dos investidores na TR, este perfil de curto prazo sc explica também pelo aumento do prazo mínimo das aplicações ós-fixadas de 30 para 90 dias junto à alta da inflação.

Num segmento do mercado de depósitos a prazo, estão grandes investidores (primeira linha) negociando em lotes elevados e auferindo altas taxas de juros. Noutro, estão as negociações de CDBs no mercado interbancário, de pouca expressão em termos de volume movimentado e, num último grupo, estão as aplicações de pequenos e médios investidores em menores lotes nas agências dos bancos e que propiciam as mais baixas taxas de rendimento.

11 Veja tambérn Bittencourt (1991 a). 
A política monetária apertada do Plano Collor contribuiu decisivamente para o aumento das aplicações em depósitos a prazo. Em março de 1990, o corte abrupto da liquidez imposto pelo bloqueio de ativos, levou os bancos a reforçar as emissões de CDBs para garantir moeda para clientes com expressivo volume de dinheiro confiscado e para assegurar a transição desse crucial instrumento de captação (Bittencourt, 1992). Em agosto de 1990, o depósito compulsório passou a incidir sobre o "floating" dos recursos nas agências bancárias. Isto levou os bancos a captar recursos para suprir as reservas, refletindo na alta das taxas de juros, o que favoreceu os depósitos a prazo ante aos demais ativos.

Em março de 1991, a proibição das aplicações com compromisso de recompra para pessoas físicas e jurídicas não-financeiras e a entrada em operação do FAF afetando a concorrência entre as instituições, foram medidas que beneficiaram as aplicações em depósitos a prazo (Bittencourt, 1992). Em agosto desse ano, a autoridade monetária instituiu o recolhimento compulsório sobre CDBs, ao nível de $100 \%$ do que ultrapassar o saldo observado em 31 de julho corrigido pela TRD mais $2 \%$ mensalmente (Circular $n^{\circ} 2020$ ). Contudo as taxas de juros mantiveram-se em elevação entre agosto e novembro em virtude da atuação restritiva do Banco Central no "overnight" e da expectativa ascendente da inflação.

Verifica-se pela Tabela 6 que, no dia 18 de novembro, um CDB prefixado de 30 dias acumulava ganho real bruto de $9,1 \%$ em 60 dias e $4,5 \%$ em 30 dias em relação à TRD. Na ponta de crédito no mesmo dia, a taxa de juros do capital de giro prefixado de 30 dias acumulava variação real de $5,4 \% \mathrm{em} 30$ dias e de $11,6 \%$ em 60 dias.

Para Bittencourt (1992), as razões que explicaram o fracasso do compulsório em conter a liquidez no mercado de depósitos a prazo foram: a capacidade dos bancos em sabstituir captações em CDBs por CDIs; a distribuição das emissões de CDBs pelas instituições ao longo do mês para não se detonar o recolhimento compulsório; e o fato da própria TR se tornar positiva em termos reais ao final de 1991 (ou seja, 30,5\% e 28,4\% em novembro e dezembro. respectivamente, contra $25,8 \%$ e $22,1 \%$ de inflaçăo medida pelo IGP/FGV).

\section{4 - CONSIDERAÇÕES FINAIS}

Depois do confisco de aplicações financeiras do Plano Collor, constatou-se notável expansão monetária em virtude da redução dos custos de retenção e do resultante aumento da demanda por moeda. 


\section{TABELA 6}

RENDIMENTO DOS CDBS E TAXAS DE JUROS DO CRÉDITO (\%) - 18 DE NOVEMBRO DE 1991 -

\begin{tabular}{l|c|c|c|c}
\hline \multicolumn{1}{c|}{ DISCRIMINAÇÃO } & $\begin{array}{c}\text { ACUMULADO } \\
\text { EM 30 DIAS }\end{array}$ & $\begin{array}{c}\text { TAXA REAL } \\
\text { EM 30 DIAS }\end{array}$ & $\begin{array}{c}\text { ACUMULADO } \\
\text { EM 60 DIAS }\end{array}$ & $\begin{array}{c}\text { TAXA REAL } \\
\text { EM 60 DIAS }\end{array}$ \\
\hline $\begin{array}{l}\text { CDB prefixado de 30 dias } \\
\text { (pessoa jurídica) }\end{array}$ & 31,6 & 4,5 & 62,6 & 9,1 \\
$\begin{array}{l}\text { CDB prefixado de 30 dias } \\
\text { (pessoas física) }\end{array}$ & 29,7 & 3,0 & 57,9 & 5,9 \\
CDB pós-fixado & & & & \\
(pessoa jurídica) & 29,6 & 2,9 & 57,9 & 5,9 \\
CDB pós-fixado & & & & \\
(pessoa física) & 28,6 & 2,1 & 55,6 & 4,4 \\
Capita! de giro & 32,7 & 5,4 & 66,3 & 11,6 \\
Desconto de duplicatas & 38,0 & 9,6 & 78,6 & 19,9 \\
Hot-money & 29,8 & 3,1 & 56,3 & 4,9 \\
TRD & 25,9 & 0,0 & 49,0 & 0,0 \\
\hline
\end{tabular}

FONTE: Abril Editora (1991).

Obs.: Pessoa juridica é isenta de IOF e Imposto de Renda na aplicação em CDBs; Capital de giro é o crédito a taxas prefixadas de prazo de 30 dias; vesconto de duplicatas é o crédito a taxas pósfixadas de prazo de 30 dias ou mais; e Hot-money é o crédito "overnight" de 1 a 7 dias.

Em maio de 1990, o governo cortou o crédito pessoal ao consumo, estabeleceu programação monetária rígida e extinguiu a garantia de recompra automática das posições diárias das instituições financeiras. Esta última medida foi, em parte, anulada pela atuação da autoridade monetária em leilões informais de venda de dinheiro para os bancos.

Ao final de 1991, nota-se que o sistema financeiro nacional registrava alto número de instituições ao lado de elevada concuntração de depósitos e empréstimos em pequeno número de grandes conglomerados bancários (Mattos, 1991). Disto resulta que deverá haver redução do númcro de bancos para a adaptação ao novo perfil mais concorrido e ligado à produção e ao mercado de capitais e menos dependente da inflação. Após o plano de estabilização já ocorreram diminuições consideráveis na rede de agências e noefetivo de funcionários do sistema bancário.

A criação do FAF como mecanismo de formação de um "funding" para o financiamento de longo prazo foi bem-vinda, dada a escassez vigente desse tipo de crédito na economia brasileira. Todavia a instabilidade macroeconômica e o descontrole dos preços impediram avanços mais significativos nesta área. $O$ mesmo pode se concluir da TR como tentativa de se criar uma taxa referencial de juros regida pelas leis do mercado para servir de piso para os custos dos 
empréstimos. Dada a volatilidade da política monetária, ocasionada pelo desequilíbrio das contas fiscais - refletindo-se na instabilidade das taxas de juros dos CDBs -, a TR ficou sujeita a oscilações que a tornaram pouco aceitável entre empresários e investidores.

Os depósitos a prazo se transformaram no principal ativo financeiro em poder do público, ultrapassando os títulos públicos federais e as cadernetas de poupança em valor de saldos. Em março de 1990, o bloqueio da liquidez levou os bancos a reforçar as captações em depósitos a prazo para satisfazer a demanda de crédito. Em agosto desse ano, a instituição do compulsório sobre "floating" das instituições, ao elevar as taxas de juros, favoreceu adicionalmente os CDBs em frente dos demais ativos. E, em março de 1991, a extinção do "overnight" para pessoas físicas e jurídicas não financeiras e a criação do FAF de rentabilidade duvidosa foram medidas que também beneficiaram as aplicações em depósitos a prazo.

Em síntese, só haverá o alongamento das aplicações financeiras e a formação de "funding" de crédito para o desenvolvimento econômico sustentável, quando houver a estabilidade da inflação. Para isso é fundamental aprofundar o ajuste fiscal e efetivar uma política de rendas que aumente a parcela do salário na renda interna. Sem tais requisitos, a poupança finaceira continuará escassa e concentrada no curto prazo.

\section{BIBLIOGRAFIA}

ABRIL EDTTORA Exame, v 23, nº 24, 27 nov. 1991, p 12.

BANCO CENTRAL. Boletim Mensal. v 27, ํ 8, ago. 1991 a.

Boletim Mensal, v.27, $n^{\circ} 9$, set $1991 b$.

Informativo Mensal, p. 1.33-1.34, ago/set. 1991c.

BITTENCOURT, Angela. Prêmio para Especulação com Risco. Gazeta Mercantil 02 nov 1991 a, p.33.

Comemorą̧ão Cautelosa e Rigor com os Juros. Gazeta Mercantil. 30 nov. 1991b, p. 25.

Conservadores Garantem Destaque ao CDB. Gazeta Mercantil, Relatorio - Balanço c Perspectivas. 02 jan. 1992,p. 9

BURLE, Lauro Lobo A Reforma Financeira e a Política Monetária Carta de Conjuntura, CORECON/DF, no 27 , jul/ago. 1991. p. 30-32. p.30-31.

As Taxas de Juros e os Depósitos a Prazo. Carta de Conjuntura, CORECON/DF, n² 29, jan./fev. 1992,

MARTONE, Celso Luiz. A Destruição do Sistema Financeiro. Economia em Perspectiva, CORECON/SP, nº 77 , jan./fev. 1991, p.4-5.

MATTOS, Elpidio Marinho Os Grandes Conseguem Manter Lucros. Gazeta Mercantil. Relatórios - Os Bancos, 26 nov. 1991, p.1-4.

MORAES, Pedro Luiz Bodin A Conduçāo da Política Monetária Durante o Plano Cruzado. Revista de Economia Política, v. 10, $\mathrm{n}^{\circ} 2,(38)$, abr /jun 1990, p.33-52.

NAKANO, Yoshiaki. As Fragilidades do Plano Collor de Estabilização. In: FARO, Clóvis de (org.). Plano Collor - Avaliação e Perspectivas. Rio de Janeiro: L.TC Editora. 1990. p.136-153.

PASTORE, Affonso Celso. A Reforma Monetária do Plano Collor. In: FARO, Clóvis de (org.) Plano Collor Avaliação e Perspectivas, Rio de Janeiro: L.TC Editora. 1990, p. 157-174. 
PEREIRA, Luiz Carlos Bresser \& NAKANO, Yoshiaki. Hiperinflaçăo e Estabilizaçăo no Brasil. Revista de Economia Política, v.11, n $^{2}$ (44), out./dez. 1991, p. 89-114.

SARTORI, Celso. Dificuldades para Conseguir Crédito. Gazeta Mercantil, 29 dez. 1990, p.28.

SIMONSEN, Mário Henrique. Um Esquema Soft Para os Cruzados. Exame, v.23, n² 14, 10 jul. 1991, p.13.

TOLEDO, Joaquim Elбi Cirne de. Financiamento de Curto Prazo no Projetão. Informações FIPE, FEAJUSP, $n^{\circledR} 129$, abr. 1991, p.7-9.

YOSHINO, Joe Akiro. Plano Collor 2: Alguns Aspectos Conceituais da Reforma Monetária (I): Informaçōes FIPE. FEAJUSP, $n^{2}$ 127, fev. 1991a, p.17-21.

. Desafios das Reformas Monetárias e Financeiras no Brasil. Informações FIPE, FEA/USP, $n^{2} 135$, out $/$ 19916. p.15-17.

.\& LUNDBERG, Eduardo Luis. Desintermediação/Repressão Financeira. Economia em Perspectiva, CORECON/SP, $n^{2} 78$, mar. 1991, p.6-7.

\section{ABSTRACT \\ THE MONETARY POLICY AND THE RATES OF INTEREST IN THE COLLOR PLAN}

This article analyses the monetary policy, the interest rates, and the applications in term deposits, during the Colle- Plan. The paper intends to show that the liquidity restriction and the inflation rate increased the shortage of long-term credit. as well as changed the term deposits in the main financial assets belonging to the private investors. 